\title{
Short-term curative effect and safety of propranolol combined with laser in the treatment of infantile hemangiomas
}

\author{
XINJUN SUN* ${ }^{*}$ XIANG LIU* ${ }^{*}$ NAN LU, SHULAN YAO, XIGUANG XU and LILI NIU \\ Department of Dermatology, Affiliated Hospital of Jining Medical University, Jining, Shandong 272000, P.R. China
}

Received March 13, 2018; Accepted August 28, 2018

DOI: $10.3892 / 01.2018 .9493$

\begin{abstract}
Short-term curative effect and safety of propranolol combined with laser in the treatment of infantile hemangiomas was studied, so as to provide reference for clinical treatment. A total of 100 cases of infantile hemangiomas admitted to the Affiliated Hospital of Jining Medical University from October 2014 to June 2016 were selected into this study. According to the random number table method, they were divided into the control group and the observation group, with 50 cases in each group. The infant patients in the control group were treated with laser alone, and the infant patients in the observation group were treated with propranolol combined with laser. The healing time, the number of times of laser therapy, the short-term curative effect, the changes in serum inflammatory factors before and after treatment and the incidence of adverse reactions were compared between the two groups of infant patients. The healing time and the times of laser therapy of the infant patients in the observation group were less than those of the infant patients in the control group, and the differences were statistically significant $(\mathrm{p}<0.05)$. The short-term curative effect of the observation group (98\%) was higher than that of the control group $(82 \%)$, and the difference was statistically significant $(\mathrm{p}<0.05)$. The levels of serum inflammatory factors interleukin (IL)-2, IL-6 and IL-10 in the two groups of infant patients after treatment were lower than those before treatment, and the levels in the observation group were lower than those in the control group, and the differences were statistically significant $(\mathrm{p}<0.05)$. Propranolol combined with laser in the treatment of infantile hemangiomas has remar kable short-term curative effects. It can effectively reduce the levels of inflammatory factors, shorten the healing time
\end{abstract}

Correspondence to: Dr Lili Niu, Department of Dermatology, Affiliated Hospital of Jining Medical University, 89 Guhuai Road, Jining, Shandong 272000, P.R. China

E-mail: niulili623@163.com

${ }^{*}$ Contributed equally

Key words: propranolol, laser, infantile hemangioma, short-term curative effect, safety and reduce the number of times of laser therapy. It is safe and worthy of clinical promotion.

\section{Introduction}

Infantile hemangiomas are mostly superficial and often exist in the infant patient's skin and subcutaneous tissues. If the infant patient has ulcers and recurrent hemorrhage, scar and functional damage, it can increase the difficulty of the treatment of infantile hemangiomas and endanger the health and safety of the infant patient (1). At present, clinical treatment methods of infantile hemangiomas are mainly steroid drugs, laser, surgery, interferon, bleomycin and vincristine. The systematic application of steroid drugs is a first-line method in the clinical treatment of hemangiomas, and it can effectively control the progress of the disease. However, the long-term application is prone to irritability, Cushing's syndrome, immune dysfunction, retarded growth and other side-effects. Moreover, the clinical curative effects of steroid drugs are controversial in clinical medicine $(2,3)$. As a non-selective $\beta$-receptor blocker, propranolol can effectively slow down or control the proliferation of hemangiomas and accelerate the regression of hemangiomas. However, its mechanism for the treatment of hemangiomas is not yet completely clear and needs further study (4). Laser, as a commonly used method for clinical treatment of hemangiomas, has remarkable clinical effects. Laser therapy for minor hemangiomas can obtain satisfactory results. Based on the above, propranolol combined with laser was adopted in the treatment of infantile hemangiomas and the application value was analyzed in this study, so as to improve the short-term curative effect and safety of the treatment of infantile hemangiomas.

\section{Materials and methods}

\section{Patients}

Inclusion criteria $(5,6)$. i) All the selected patients were clinically diagnosed with infantile hemangiomas and all of them were single hemangiomas. ii) Patients without drug allergy history or allergic constitution. iii) Patients who had not received special treatment prior to the study, such as freezing, hormone, injection of sclerosing agent and nuclide application. iv) Patients with no neurological diseases, blood system diseases and other benign and malignant tumors. v) The present study was approved by the Ethics Committee of the Affiliated 
Hospital of Jining Medical University (Jining, China); and vi) The parents of the infant patients were informed of the study and signed the informed consent.

Exclusion criteria (7). i) Patients with light allergy. ii) Patients with cicatricial diathesis. iii) Patients with bleeding or coagulation disorders. iv) Patients with vascular malformations, visceral hemangiomas, thrombocytopenic purpura and other related syndromes. v) Involuntary participants; and vi) Those with low treatment cooperation.

General data. A total of 100 cases of infantile hemangiomas admitted to the Affiliated Hospital of Jining Medical University from October 2014 to June 2016 were selected into this study, and all of them met the inclusion criteria. According to the random number table method, they were divided into the control and observation groups, with 50 cases in each group. There were 22 males and 28 females in the control group, at the age of 1-7 months, with an average age of 3.6 \pm 1.2 months, including 19 cases of superficial hemangiomas, 31 cases of mixed hemangiomas. There were 20 males and 30 females in the observation group, at the age of 1-6 months, with an average age of $3.4 \pm 1.5$ months, including 21 cases of superficial hemangiomas and 29 cases of mixed hemangiomas. There were no statistically significant differences in basic data between the two groups of infant patients, and the data were comparable $(\mathrm{p}>0.05)$.

Methods. The infant patients in the observation group were treated with propranolol combined with laser, while the infant patients in the control group were treated with laser alone (laser method was the same as that in the observation group). The two groups of infant patients were followed up for 3-6 months.

Propranolol. Before treatment, the infant patients underwent related auxiliary examinations such as blood routine, electrolytes, chest radiograph, liver and kidney function, cardiac enzymes, electrocardiogram and B-ultrasound of tumor location, and computed tomography angiography (CTA) and magnetic resonance angiography (MRA) were performed if necessary. The infant patients with normal blood routine, electrolytes, chest radiograph, liver and kidney function, cardiac enzymes and electrocardiogram were guided and helped to take propranolol (NMPN H61020344; Shaanxi Yongshou Pharmaceutical Co., Ltd., Shaanxi, China) orally, at $1.0 \mathrm{mg} /(\mathrm{kg} \cdot \mathrm{d})$ divided into 3 doses on the first day. The infant patients were observed, and if no special discomfort occurred, propranolol was given at $1.5 \mathrm{mg} /(\mathrm{kg} \cdot \mathrm{d})$ divided into 3 doses on the second day. The infant patients were observed, and if no special discomfort occurred, propranolol was given at $2.0 \mathrm{mg} /(\mathrm{kg} \cdot \mathrm{d})$ divided into 3 doses on the third day. The infant patients' vital signs were monitored closely during treatment, and the normal group continued to take the dose according to the dose of the third day. The infant patients were given blood routine, electrolytes, liver and kidney function, cardiac enzymes and electrocardiogram reexamination every 2-3 weeks during initial medication time. If there was no abnormal occurrence after oral medication for 2 months, the reexamination interval was changed to 1 month. B-ultrasound reexamination of tumor location was conducted if necessary.
Table I. Comparisons of the healing time and the times of laser therapy between the two groups of infant patients (means \pm SD).

\begin{tabular}{lcc}
\hline Groups & $\begin{array}{c}\text { Healing time } \\
\text { (month) }\end{array}$ & $\begin{array}{c}\text { Times of laser } \\
\text { therapy (times) }\end{array}$ \\
\hline Control $(\mathrm{n}=50)$ & $12.6 \pm 4.7$ & $7.4 \pm 1.2$ \\
Observation $(\mathrm{n}=50)$ & $8.7 \pm 2.5$ & $6.9 \pm 0.8$ \\
t-test & 5.180 & 2.452 \\
P-value & $<0.05$ & $<0.05$ \\
\hline
\end{tabular}

Laser. The long-pulse 1,064 nm Nd:YAG laser was used for the therapy, with light spot of $9 \mathrm{~mm}$, by the application of contact synchronous cooling technology. The laser parameters were set as follows: the pulse width was $12 \mathrm{msec}$, single pulse, and the energy density was $40-70 \mathrm{~J} / \mathrm{cm}^{2}$. The low energy density was used in the first treatment of the infant patients, and the energy density was gradually increased according to the changes of the lesions in the infant patients, so as to ensure that the overlap of each spot was $<10 \%$. The endpoint of treatment was as follows: the local temperature of the tumor was slightly increased; the volume of the tumor was slightly increased or decreased; the original skin color (red) of the tumor was darkened or shallower, and the texture of the tumor became soft. After treatment, the infant patients were treated with intermittent cold compress with soft ice bags, $20 \mathrm{~min}$ each time, with continuous ice compress for 3 days. The next treatment was performed every 3 weeks until the skin lesions subsided. If there was obvious edema in the treatment site of the infant patients, appropriate amount of prednisone could be given for 3-5 days.

Observation indexes. The healing time, the number of times of laser therapy, the short-term curative effect, the changes in serum inflammatory factors before and after treatment and the incidence of adverse reactions were observed and analyzed between the two groups of infant patients. i) Short-term curative effect: the curative effects were evaluated according to the grading standards formulated by a previous report (8) as follows: cured: the tumor body in the infant patients was decreased by $\geq 76.0 \%$ after treatment. Markedly effective: the tumor body in the infant patients was decreased by $51.0-75.0 \%$ after treatment. Effective: the tumor body in the infant patients was decreased by $26.0-50.0 \%$ after treatment. Ineffective: the tumor body in the infant patients was decreased by $<25.0 \%$ after treatment. ii) Serum inflammatory factors (9): including interleukin (IL)-2, IL-6 and IL-10. In the two groups of infant patients, $3 \mathrm{ml}$ elbow blood was extracted in fasting state before and after treatment, and centrifuged at $1,750 \mathrm{x} \mathrm{g}$ for $15 \mathrm{~min}$ at $4^{\circ} \mathrm{C}$. The serum was separated and the supernatant was collected. Serum inflammatory factors were detected by enzyme-linked immunosorbent assay. iii) Adverse reactions (10): including ulcers, decreased heart rate, decreased appetite, mild high potassium, nausea and vomiting.

Statistical analysis. Statistical Product and Service Solutions (SPSS) 20.0 statistical software (IBM Corp., Armonk, NY, USA) was adopted for data analysis. The enumeration data 


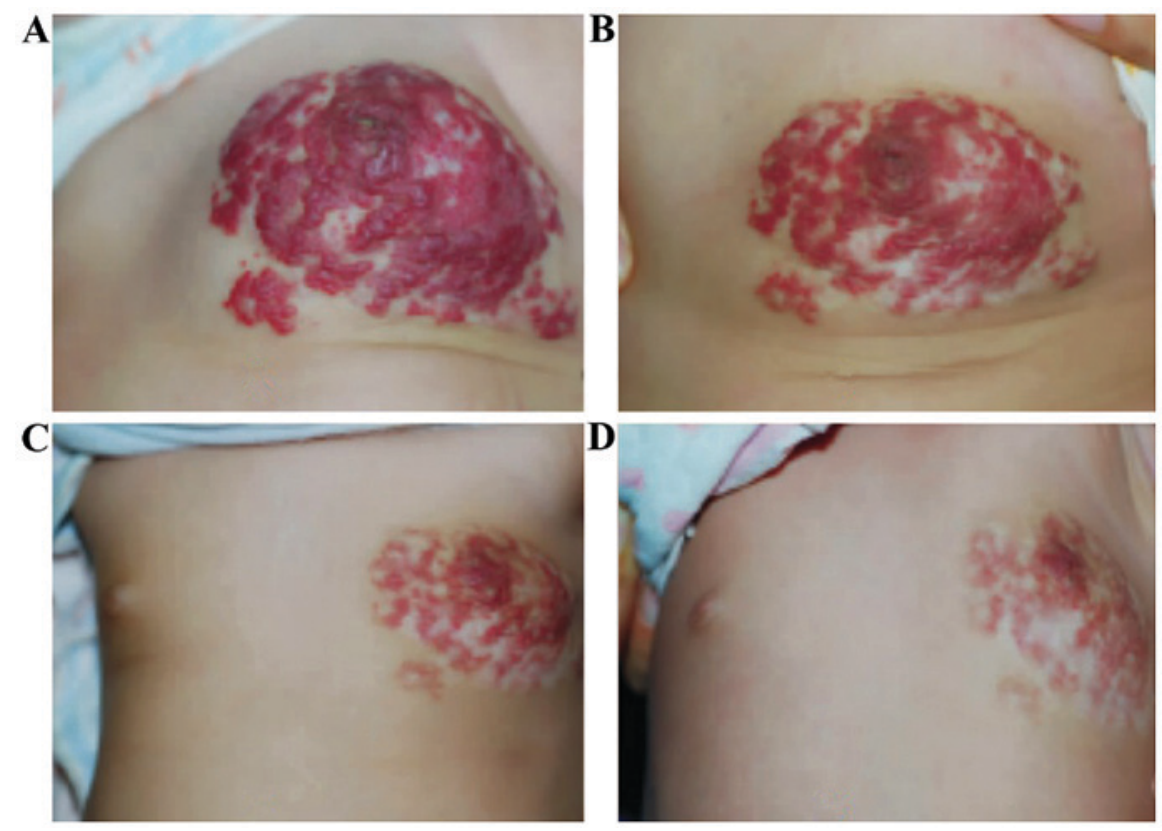

Figure 1. Anterior and posterior infantile hemangiomas on the left side of the chest before propranolol combined with laser treatment. (A) Before treatment, (B) after 1 month of protolyllol treatment, (C) laser therapy after 5 months of propranolol treatment and (D) after 1 month of laser therapy.

Table II. Comparison of the short-term curative effect of the two groups of infant patients (n, \%).

\begin{tabular}{lccccc}
\hline Groups & Cured & Markedly effective & Effective & Ineffective & Total effective rate \\
\hline Control $(\mathrm{n}=50)$ & $9(18.0)$ & $21(42.0)$ & $11(22.0)$ & $9(18.0)$ & $41(82.0)$ \\
Observation $(\mathrm{n}=50)$ & $15(30.0)$ & $26(52.0)$ & $8(16.0)$ & $1(2.0)$ & $49(98.0)$ \\
$\chi^{2}$ & - & - & - & - & 7.111 \\
P-value & - & - & - & - & $<0.05$ \\
\hline
\end{tabular}

were expressed as percentages and cases, and $\chi^{2}$ test was used for comparisons between the groups. The measurement data are expressed as (means $\pm \mathrm{SD}$ ), and t-test was used for comparisons between the groups. $\mathrm{P}<0.05$ indicates that the difference was statistically significant.

\section{Results}

Healing time and the number of times of laser therapy. The healing time and the times of laser therapy of the infant patients in the observation group were less than those of the infant patients in the control group, and the differences were statistically significant $(\mathrm{p}<0.05)($ Table I).

Short-term curative effect. The short-term curative effect of the observation group $[98.00 \%$ (49/50)] was higher than that in the control group [82.00\% (41/50)], and the difference was statistically significant $(\mathrm{p}<0.05)$ (Table II, Fig. 1).

Serum inflammatory factors. The levels of serum inflammatory factors IL-2, IL-6 and IL-10 in the two groups of infant patients after treatment were lower than those before treatment, and they were lower in the observation group than those in the control group, and the differences were statistically significant $(\mathrm{p}<0.05)$ (Table III).
Table III. Changes in levels of serum inflammatory factors before and after treatment in the two groups of infant patients (means \pm SD).

\begin{tabular}{|c|c|c|c|c|}
\hline Groups & $\begin{array}{l}\text { Control } \\
(\mathrm{n}=50)\end{array}$ & $\begin{array}{l}\text { Observation } \\
\quad(\mathrm{n}=50)\end{array}$ & t-test & P-value \\
\hline \multicolumn{5}{|l|}{ IL- $2 / \beta$-actin } \\
\hline Before treatment & $0.89 \pm 0.17$ & $0.91 \pm 0.14$ & 0.642 & $>0.05$ \\
\hline After treatment & $0.63 \pm 0.21$ & $0.36 \pm 0.08$ & 16.875 & $<0.05$ \\
\hline t-test & 6.805 & 24.119 & & \\
\hline P-value & $<0.05$ & $<0.05$ & & \\
\hline \multicolumn{5}{|l|}{ IL- $6 / \beta$-actin } \\
\hline Before treatment & $0.55 \pm 0.11$ & $0.56 \pm 0.08$ & 0.520 & $>0.05$ \\
\hline After treatment & $0.39 \pm 0.07$ & $0.25 \pm 0.05$ & 11.508 & $<0.05$ \\
\hline t-test & 8.677 & 23.23 & & \\
\hline P-value & $<0.05$ & $<0.05$ & & \\
\hline \multicolumn{5}{|l|}{ IL-10/ß-actin } \\
\hline Before treatment & $0.77 \pm 0.24$ & $0.79 \pm 0.16$ & 0.490 & $>0.05$ \\
\hline After treatment & $0.56 \pm 0.12$ & $0.40 \pm 0.09$ & 7.543 & $<0.05$ \\
\hline t-test & 5.534 & 15.022 & & \\
\hline P-value & $<0.05$ & $<0.05$ & & \\
\hline
\end{tabular}

IL, interleukin. 
Table IV. Comparison of the incidence of adverse reactions between the two groups of infant patients (n, \%).

\begin{tabular}{lcccccc}
\hline Groups & Ulcer & $\begin{array}{c}\text { Decreased } \\
\text { heart rate }\end{array}$ & $\begin{array}{c}\text { Decreased } \\
\text { appetite }\end{array}$ & $\begin{array}{c}\text { Mild high } \\
\text { potassium }\end{array}$ & $\begin{array}{c}\text { Nausea and } \\
\text { vomiting }\end{array}$ & $\begin{array}{c}\text { Total } \\
\text { incidence }\end{array}$ \\
\hline Control $(\mathrm{n}=50)$ & $1(2.0)$ & $2(4.0)$ & $1(2.0)$ & $0(0.0)$ & $0(0.0)$ & $4(8.0)$ \\
Observation $(\mathrm{n}=50)$ & $1(2.0)$ & $2(4.0)$ & $2(4.0)$ & $0(0.0)$ & $0(0.0)$ & $5(10.0)$ \\
$\chi^{2}$ & - & - & - & - & - & - \\
P-value & - & - & - & - & - & $>0.05$ \\
\hline
\end{tabular}

Adverse reactions. There was no statistically significant difference in the incidence of adverse reactions between the two groups of infant patients ( $\mathrm{p}>0.05)$ (Table IV).

\section{Discussion}

Infantile hemangiomas are common benign tumors in infants and children. Under normal circumstances, it does not exist when the infant is born. Most of infantile hemangiomas grow fast within 3-12 months and disappear spontaneously after 3-7 years. The incidence rate is $10-12 \%$ in the newborns and $>20 \%$ in the underweight premature infants, mostly in female infants $(11,12)$. It has been found that hemangiomas easily affect the esthetics of the body, and can cause ulcers and other related reactions, even the risk of death in serious cases. Currently, propranolol and laser are important methods for the clinical treatment of infantile hemangiomas, and they can effectively control the progression of the disease and reduce the risk of adverse reactions. However, the specific mechanisms for treatment are not yet completely clear and remain to be further studied (13).

Propranolol, as a commonly used non-selective $\beta$-receptor blocker, is commonly used in the treatment of hypertension and supraventricular tachycardia, hyperthyroidism, angina pectoris and other cardiovascular diseases (14). The peak plasma concentration can be reached in patient at 1-3 h after oral administration, and its half-life is approximately 3.0-6.0 h. The relevant mechanisms are mainly that it can promote vasoconstriction, inhibit angiogenesis and induce apoptosis of related endothelial cells (15). At the same time, propranolol can reduce the release of nitric oxide to contract peripheral blood vessels at the early stage of treatment. With the prolongation of treatment, Raf mitogen is gradually downregulated, and protein kinase pathway is activated, and the expression of basic fibroblast growth factor (bFGF) and vascular endothelial growth factor (VEGF) is decreased, and the hemangiomas further subside. Moreover, by antagonizing the glut receptor, or acting on other related unknown pathways, propranolol can accelerate the apoptosis of vascular endothelial cells, thereby promoting the regression of the tumor $(16,17)$.

Laser is a commonly used method for clinical treatment of hemangiomas, mainly based on the selective photothermolysis in the treatment of vascular diseases. Hemangioma endothelial cells are the targets, and oxyhemoglobin and deoxyhemoglobin are the color bases, both of which have many absorption peaks (8). A study has shown that the pulsed dye laser wavelengths are 585 and $595 \mathrm{~nm}$, which are close to oxyhemoglobin absorption peak. They can induce specific thermal damage to the abnormal dilated blood vessels, cause no damage to the adjacent skin tissues, and can further promote the regression of hemangiomas. However, the penetration depth is shallow at $1-2 \mathrm{~mm}$ and the epidermal melanin is absorbed completely, combined with the impact of purpura, all of which can limit the application of pulsed dye laser in the treatment of some hemangiomas with deeper location and thicker tumor body (18). The wavelength of $1,064 \mathrm{~nm}$ is at another absorption peak with a deeper penetrating power and has no significant effect on the epidermal melanin barrier. Therefore, the long-pulse 1,064 nm Nd:YAG laser therapy has a better curative effect in the treatment of hemangiomas with a certain depth and thickness, and has no side-effects such as purpura, and the side-effect of epidermis is smaller (19). Therefore, propranolol combined with laser in the treatment of hemangiomas can effectively improve the curative effects. The results in this study showed that, after treatment, the healing time and the number of times of laser therapy of the infant patients in the observation group were less than those in the control group. The short-term curative effect was higher than that in the control group. The levels of inflammatory factors were lower than those in the control group. However, there was no significant difference in the incidence of adverse reactions between the two groups of infant patients. The results suggested that propranolol combined with laser in the treatment of infantile hemangiomas has remarkable curative effects and high safety, and it can effectively shorten the healing time, reduce the number of times of laser therapy and the expression of inflammatory factors, and promote the rehabilitation of infant patients. However, the sample size in this study was small. Consequently, the observation time was short, and the long-term curative effect and safety of the infant patients were not analyzed. At the same time, random grouping may result in a certain bias on the results. In-depth study should be carried out in the future by increasing the sample size.

In summary, the application of propranolol combined with laser in the treatment of infantile hemangiomas has remarkable short-term curative effects, high safety and fewer side-effects. It can effectively reduce the levels of inflammatory factors, accelerate the regression of hemangiomas, shorten the healing time of the infant patients, reduce the number of times of laser therapy, and promote the rehabilitation of the infant patients. Therefore, it is worthy of clinical promotion.

\section{Acknowledgements}

Not applicable. 


\section{Funding}

No funding was received.

\section{Availability of data and materials}

The datasets used and/or analyzed during the present study are available from the corresponding author on reasonable request.

\section{Authors' contributions}

XS and XL wrote and finalized this manuscript. XS and XL were also involved in the conception and design of the study. NL helped with the patient data collection. SY performed the laser treatment. XX and LN recorded and analyzed the observation indexes. All authors read and approved the final manuscript.

\section{Ethics approval and consent to participate}

The study was approved by the Ethics Committee of the Affiliated Hospital of Jining Medical University (Jining, China). Patients who participated in this research had complete clinical data. Signed informed consents were obtained from the parents of the patients.

\section{Patient consent for publication}

Not applicable.

\section{Competing interests}

The authors declare that they have no competing interests.

\section{References}

1. Shah S and Frieden IJ: Treatment of infantile hemangiomas with beta-blockers: A review. Skin Therapy Lett 18: 5-7, 2013.

2. Williams EF III, Hochman M, Rodgers BJ, Brockbank D, Shannon L and Lam SM: A psychological profile of children with hemangiomas and their families. Arch Facial Plast Surg 5: 229-234, 2003.

3. Manunza F, Syed S, Laguda B, Linward J, Kennedy H, Gholam K, Glover M, Giardini A and Harper JI: Propranolol for complicated infantile haemangiomas: A case series of 30 infants. Br J Dermatol 162: 466-468, 2010.

4. Léauté-Labrèze $\mathrm{C}$, Dumas de la Roque $\mathrm{E}$, Hubiche $\mathrm{T}$, Boralevi $\mathrm{F}$, Thambo JB and Taïeb A: Propranolol for severe hemangiomas of infancy. N Engl J Med 358: 2649-2651, 2008.

5. Storch $\mathrm{CH}$ and Hoeger PH: Propranolol for infantile haemangiomas: Insights into the molecular mechanisms of action. Br J Dermatol 163: 269-274, 2010.

6. Haggstrom AN, Drolet BA, Baselga E, Chamlin SL, Garzon MC, Horii KA, Lucky AW, Mancini AJ, Metry DW, Newell B, et al: Prospective study of infantile hemangiomas: Clinical characteristics predicting complications and treatment. Pediatrics 118 : $882-887,2006$
7. Frieden IJ, Haggstrom AN, Drolet BA, Mancini AJ, Friedlander SF, Boon L, Chamlin SL, Baselga E, Garzon MC, Nopper AJ, et al: Infantile hemangiomas: Current knowledge, future directions. Proceedings of a research workshop on infantile hemangiomas, April 7-9, 2005, Bethesda, MA. Pediatr Dermatol 22: 383-406, 2005.

8. Chim H, Armijo BS, Miller E, Gliniak C, Serret MA and Gosain AK: Propranolol induces regression of hemangioma cells through HIF-1 $\alpha$-mediated inhibition of VEGF-A. Ann Surg 256: $146-156,2012$.

9. Taraboletti G, Sonzogni L, Vergani V, Hosseini G, Ceruti R, Ghilardi C, Bastone A, Toschi E, Borsotti P, Scanziani E, et al: Posttranscriptional stimulation of endothelial cell matrix metalloproteinases 2 and 1 by endothelioma cells. Exp Cell Res 258: 384-394, 2000.

10. Arevalo JF, Shields CL, Shields JA, Hykin PG and De Potter P: Circumscribed choroidal hemangioma: Characteristic features with indocyanine green videoangiography. Ophthalmology 107: 344-350, 2000

11. Vergani V, Garofalo A, Bani MR, Borsotti P, Parker MP, Drudis T, Mazzarol G, Viale G, Giavazzi R, Stetler-Stevenson WG, et al: Inhibition of matrix metalloproteinases by over-expression of tissue inhibitor of metalloproteinase- 2 inhibits the growth of experimental hemangiomas. Int J Cancer 91: 241-247, 2001.

12. Chai Q, Chen WL, Huang ZQ, Zhang DM, Fan S and Wang L: Preliminary experiences in treating infantile hemangioma with propranolol. Ann Plast Surg 72: 169-172, 2014.

13. Selmin A, Foltran F, Chiarelli S, Ciullo R and Gregori D: An epidemiological study investigating the relationship between chorangioma and infantile hemangioma. Pathol Res Pract 210: 548-553, 2014.

14. Adler AP, Daly C, Parveen AA, Nevins T, Shan J, Fairhurst J, Huang T, Martin J, Papadopoulos N, Yancopoulos GD, et al: Blockade of angiopoietin-2 or Tie2 is equally effective at inhibiting tumor growth and reducing tumor vessel density in most human tumor xenograft models. Cancer Res (AACR Annual Meeting 2014) 74 (19 Suppl): Abst 4492, 2014.

15. Lomas-Neira JL, Heffernan DS, Ayala A and Monaghan SF: Blockade of endothelial growth factor, angiopoietin-2, reduces indices of ARDS and mortality in mice resulting from the dual-insults of hemorrhagic shock and sepsis. Shock 45: 157-165, 2016.

16. Tal R, Seifer DB, Grazi RV and Malter HE: Angiopoietin-1 and angiopoietin-2 are altered in polycystic ovarian syndrome (PCOS) during controlled ovarian stimulation. Vasc Cell 5: 18, 2013.

17. Yue CH, Shu H, Feng JH and Zhang DY: The efficacy and safety of oral propranolol combination with topical application of timolol maleate eye drops on infant hemangioma. J Dermatol Venereol 27: 179-184, 2015.

18. Lee D, Boscolo E, Durham JT, Mulliken JB, Herman IM and Bischoff J: Propranolol targets the contractility of infantile haemangioma-derived pericytes. Br J Dermatol 171: 1129-1137, 2014.

19. Emiralioğlu N, Oğuz B, Akyüz C, Yalçın B, Kiper N, Ersöz DD, Yalçın E and Özçelik U: Successful treatment of pulmonary hemangioma with propranolol. Pediatr Pulmonol 49: 829-833, 2014. 